Tropical Journal of Pharmaceutical Research September 2016; 15 (9): 1995-1999

ISSN: 1596-5996 (print); 1596-9827 (electronic)

(C) Pharmacotherapy Group, Faculty of Pharmacy, University of Benin, Benin City, 300001 Nigeria.

All rights reserved.

Available online at http://www.tjpr.org

Original Research Article

http://dx.doi.org/10.4314/tjpr.v15i9.25

\title{
Gender-specific association of MSA2756G with hypertension in patients attending a health facility in Ningxia Province, China
}

\author{
Xiu-fang Wang ${ }^{1}$, Ying-hong Liao ${ }^{1}$, Yi Cai $^{1 *}$, Ju-yi Li ${ }^{2}$ \\ ${ }^{1}$ Department of Pain, ${ }^{2}$ Department of Pharmacy, The Central Hospital of Wuhan, Wuhan, Hubei Province, 430021, China \\ *For correspondence: Email: cy21722@126.com
}

Received: 9 June 2016

Revised accepted: 22 August 2016

\begin{abstract}
Purpose: To investigate the distribution of methionine synthase A2756G (MSA2756G) in the hypertensive patients in northwest Chinese population.

Methods: A total of 378 unrelated hypertensive patients attending Ningxia Peoples Hospital, Ningxia Province, China, were recruited for this study. We analyzed genotype by amplication - created restriction sites (ACRS) and polymerase chain reaction - restrict fragment length polymorphism (PCR $R F(P)$ in hypertensive patients, and inspected the relation of the genotype with hypertension by $x^{2}$ and $t$ test.

Results: The frequency of $G$ allele was $10.25 \%$ in the control group and $14.04 \%$ in hypertension group; it was not statistically different $(p>0.05)$. In the male group, the frequency of allele $G$ was 11.50 $\%$ in control group, and $8.79 \%$ in hypertension group. There was no significant difference between control and hypertension groups ( $p>0.05$ ). In the female group, the frequency of allele $G$ was $9.00 \%$, in control and $19.54 \%$ in hypertension group $(p<0.05)$, while in the hypertension group, allele $G$ was $8.79 \%$ in males which is significantly lower $(p<0.05)$ than in females $(19.54 \%)$.

Conclusion: Allele $G$ of MSA2756G is a risk factor for hypertension in female in this Chinese population of this study.
\end{abstract}

Keywords: Hypertension, Methionine synthase, Polymorphism, Gender, Amplification-created restriction sites, Allele G, MSA2756G

Tropical Journal of Pharmaceutical Research is indexed by Science Citation Index (SciSearch), Scopus, International Pharmaceutical Abstract, Chemical Abstracts, Embase, Index Copernicus, EBSCO, African Index Medicus, JournalSeek, Journal Citation Reports/Science Edition, Directory of Open Access Journals (DOAJ), African Journal Online, Bioline International, Open-J-Gate and Pharmacy Abstracts

\section{INTRODUCTION}

Hypertension is a major global public health problem due to its high prevalence and its association with morbidity and mortality from stroke and coronary diseases [1,2]. In China, it was reported that $27.2 \%$ of adults aged $35-74$ years suffer from hypertension [3]. High blood pressure is regarded as a complex condition to which genetic, environmental, and demographic factors contribute interactively [4].
To date, there have been many studies to search for hypertension susceptibility genes, but only little information about it is available. In order to determine the pathogenesis of hypertension and to device a novel treatment method, it is essential to find new genes associated with hypertension.

Methionine synthase (MS) is a key enzyme in the homocysteine (Hcy) re - methylation pathway. Genetic variations of MS genes may significantly affect Hcy metabolism. An enhanced function of 
MS will lead to a decreased plasma Hcy level. An $A$ - to - G substitution of the MS gene (MSA2756G), which results in the conversion of an aspartic acid residue to a glycine residue, was found to play a role in regulating plasma Hcy levels [5]. Hcy was also found to be associated with blood pressure levels in several studies [58]. In the light of these findings, MS gene polymorphism might also be a possible underlying mechanism in blood pressure.

MSA2756G gene seems to be an attractive candidate gene for hypertension. In the present study, our aims were to investigate the association between MSA2756G and the risk of $\mathrm{EH}$ in Chinese Hui population.

\section{METHODS}

\section{Subjects}

In all, 378 unrelated Chinese (187 females, 191 males) were randomly recruited at Ningxia Peoples Hospital in Ningxia Province, China, including 178 hypertensive patients (87 females, 91 males; mean age $46.06 \pm 6.90$ years) and 200 healthy volunteers (100 females, 100 males; mean age $46.22 \pm 9.25$ years). All subjects completed a standard questionnaire on personal medical history and family history of hypertension. Hypertension was defined as mean systolic blood pressure (SBP) $\geq 140$ $\mathrm{mmHg}$ and/or mean diastolic blood pressure $(\mathrm{DBP}) \geq 90 \mathrm{mmHg}$ and/or self - reported current treatment for hypertension with antihypertensive medication. Subjects with secondary hypertension, primary renal disease, diabetes mellitus, hepatic disorders, cancers or endocrine diseases were excluded. This study complied with Declaration of Helsinki [9]. All participants involved gave their written informed consent for the genetic analysis and the study was approved by the Ethics Committee of Ningxia Peoples Hospital (approval ref. no. 20120101).

\section{Genotyping}

Genomic DNA was extracted from white blood cells via phenol and chloroform extraction and ethanol precipitation essentially following standard protocols. MSA2756G genotype was determined by means of PCR - RFLP. Primers for PCR were all synthesized by GeneCore Bio Technologies (Shang Hai, China). The sequences and reverse primers used were 5' CATGGAAGAATATGAAGATATTAGAC - 3' and 5' - GAACTAGAAGACAGAAATTCTCTA - 3'. PCR was performed using $50 \mathrm{ng}$ DNA as a template under the following conditions: $94{ }^{\circ} \mathrm{C}$ for $5 \mathrm{~min}$, then 35 cycles of $94{ }^{\circ} \mathrm{C}$ for $50 \mathrm{~s}$, an annealing temperature at $56{ }^{\circ} \mathrm{C}$ for $60 \mathrm{~s}$, and extension at $72{ }^{\circ} \mathrm{C}$ for $1 \mathrm{~min}$, with a final extension at $72{ }^{\circ} \mathrm{C}$ for $7 \mathrm{~min}$. The amplified DNA fragment was digested with restriction enzymes Hae at $37{ }^{\circ} \mathrm{C}$ for $12 \mathrm{~h}$. The DNA fragments of MSA2756G was separated by $4 \%$ agarose gel electrophoresis and were detected by ethidium bromide staining.

\section{Statistical analysis}

Statistical analysis was performed using SPSS 11.5 software. The results are expressed as mean \pm standard deviation (SD). Allele frequencies were compared by Chi - square test with Yates' correction, while an independent $t$ test was used to compare the two groups. $P<$ 0.05 was considered as statistically significant.

\section{RESULTS}

\section{Characteristics of the subjects}

The clinical and laboratory characteristics of cases and controls were shown in Table 1. The subjects were adequately matched for age and gender for hypertensive cases and controls. The following variables were significantly higher in hypertensive patients: SBP, DBP. No significant differences were found for the following values between the hypertensive patients and the control subjects: age, number of the subjects.

\section{MSA2756G genotype and allele frequencies in hypertensive patients and healthy control}

As shown in Table 2, The MS 2756G allele frequency in our study was $12.04 \%$. G frequency was higher in hypertensive patients (14.04\%) compared to the control $(10.25 \%, p>0.05)$,

Table 1: Characteristics of hypertensive patients and healthy control (mean \pm SD)

\begin{tabular}{lll}
\hline Variable & Hypertensive patients & Healthy control \\
\hline Number (male/female) & $178(91 / 87)$ & $200(100 / 100)$ \\
Mean age (years) & $46.06 \pm 6.90$ & $46.22 \pm 9.25$ \\
SBP $(\mathrm{mmHg})$ & $149.10 \pm 15.04$ & $103.63 \pm 5.58^{\pi}$ \\
DBP $(\mathrm{mmHg})$ & $95.26 \pm 10.75$ & $72.23 \pm 2.45^{\star}$ \\
\hline
\end{tabular}

Compared with control, $p<0.01$ 
Table 2: Frequencies of genotypes and alleles of MSA2756G in hypertensive patients and healthy control

\begin{tabular}{|c|c|c|c|c|c|}
\hline \multirow{2}{*}{ Group } & \multicolumn{3}{|c|}{ Genotype } & \multicolumn{2}{|c|}{ Allele } \\
\hline & $A A(\%)$ & AG (\%) & GG (\%) & $A(\%)$ & G (\%) \\
\hline $\begin{array}{l}\text { Hypertensive patients ( } \\
n=178)\end{array}$ & $135(75.85 \%)$ & $36(20.22 \%)$ & $7(3.93 \%)$ & $306(85.96 \%)$ & $50(14.04 \%)^{*}$ \\
\hline $\begin{array}{l}\text { Healthy control } \quad(n=200 \\
\text { ) }\end{array}$ & $162(81.00 \%)$ & $35(17.50 \%)$ & $3(1.50 \%)^{*}$ & $359(89.75 \%)$ & $41(10.25 \%)$ \\
\hline
\end{tabular}

Table 3: Frequencies of genotypes and alleles of MSA2756G in hypertensive patients and healthy control

\begin{tabular}{|c|c|c|c|c|c|c|}
\hline \multirow[t]{2}{*}{ Gender } & \multirow[t]{2}{*}{ Group } & & \multicolumn{2}{|c|}{ Genotype } & \multicolumn{2}{|l|}{ Allele } \\
\hline & & AA (\%) & AG (\%) & GG（\%） & A (\%) & G (\%) \\
\hline \multirow[t]{2}{*}{ Male } & $\begin{array}{l}\text { Hypertensive patients ( } \\
\mathrm{n}=91 \text { ) }\end{array}$ & $79(86.81 \%)$ & $8(8.87 \%)$ & $4(4.40 \%)$ & $166(91.21 \%)$ & $16(8.79 \%)$ \\
\hline & Healthy control $(n=100)$ & $79(79.00 \%)$ & $19(19.00 \%)$ & $2(2.00 \%)$ & $177(88.50 \%)$ & $23(11.50 \%)$ \\
\hline \multirow[t]{2}{*}{ Female } & $\begin{array}{l}\text { Hypertensive patients ( } \\
\mathrm{n}=87)\end{array}$ & $56(64.37 \%)$ & $28(32.18 \%)$ & $3(3.45 \%)$ & $140(80.46 \%)$ & $\begin{array}{c}34(19.54 \\
\%)^{*}\end{array}$ \\
\hline & Healthy control $(n=100)$ & $83(83.00 \%)$ & $16(16.00 \%)$ & $1(1.00 \%)$ & $182(91.00 \%)$ & $18(9.00 \%)$ \\
\hline
\end{tabular}

Compared with control in female group; ${ }^{*} p<0.01$, compared with female hypertensive patients, ${ }^{\star *} p<0.01$

the $A G+G G$ genotype frequency in hypertensive patients was higher than in those with AA genotype compared with control $(p>$ 0.05 ), indicating that $G$ allele was not associated with hypertension.

\section{Distribution of MSA2756G}

A non - significant difference was observed in the frequencies of MSA2756G between hypertensive patients and healthy control in the male group (8.79 \% vs $11.50 \%, p>0.05)$, whereas in the female group, the frequency of MSA2756G in hypertensive patients was significantly higher than that in healthy control (19.54\% vs $9.00 \%, p$ $<0.01)$. Allele $G$ frequency in female group was higher than in male group in hypertensive patients (19.54 \% vs $8.79 \%, p<0.01)$, whereas a non - significant difference was observed in healthy control (9.00\% vs $11.50 \%, p>0.05)$. This indicate a gender specific association of MSA2756G with hypertension, the allele $G$ of MSA2756G was a risk factor for hypertensive disease in female group (Table 3).

\section{DISCUSSION}

MS plays an important role in Hcy metabolism as a key enzyme in the homocysteine remethylation pathway. The MS gene has been cloned, sequenced and located, and several polymorphisms have also been identified. The most prevalent polymorphism is the A2756G SNP which results in the conversion of an aspartic acid residue to a glycine residue [10]. The MS 2756G allele in our Chinese Hui population $(12.04 \%)$ was similar to the frequencies in Singapore (11.0\%) [10], Thailand (11.8\%) [11] and Koreans (13.1\%) [12]. The MS 2756G allele frequency in our study was lower than in Japanese (17.3 \%) [13], Hispanics (18.8 $\%$ ), and Caucasians (19.9\%) [14], which was half of that in African Americans (23.8\%) [14] and Northern Indians (24\%) [15], Indians (26.4 $\%$ ) [10]. The MS $2756 \mathrm{G}$ allele is common but also heterogeneously distributed among the world's populations.

In this study, we demonstrated that in the female group, the frequency of MSA2756G in hypertensive patients $(19.54 \%)$ was significantly higher than that in healthy control $(9.00 \%), p<$ 0.01. In Hypertensive patients, allele $G$ frequency in female group was higher than in male group ( $p$ $<0.01$ ). The present study indicated a gender specific association of MSA2756G with hypertension, allele $G$ was a risk factor for hypertensive disease in female group. A previous study found that MS A2756G mutation may be a risk factor for combined hyperlipidemia [16]. Some studies have indicated that MS 2756G allele was related to higher Hcy level, the MS A / $\mathrm{G}$ or $\mathrm{G} / \mathrm{G}$ genotype was considered a genetic risk factor for elevated Hcy level [10]. D919G polymorphism of the MTR gene may be a useful genetic marker to predict the antihypertensive effect of short - term benazepril therapy in hypertensive patient $[5,6]$.

Arterial hypertension is an important risk factor for cardio - and cerebrovascular disease. A previous study found significant association the MTR c. $2576 \mathrm{~A}>\mathrm{G}$ polymorphism diastolic blood pressure [8]. Kahleova et al found that carriers of the G - allele of the MTR c. 2756A > G 
polymorphism had a reduced risk of juvenile hypertension [17]. Brett et al found a significant effect of methionine loading on diastolic blood pressure during exercise resulting in higher diastolic blood pressure [18]. The mechanisms by which the MS genotype influences diastolic blood pressure, but apparently not systolic blood pressure, are still unknown.

MS catalyzes the remethylation of homocysteine to methionine and has influence on DNA methylation as well as on nucleic acid synthesis, the missense polymorphism MS c. 2756A > G (D919G) has been reported to alter the susceptibility to various cancers [19]. In summary, our study showed that the allele $G$ of MSA2756G was an risk factor for hypertension in the female, it suggest that women carried allele $G$ of MSA2756G should be pay more attentions in life, in order to prevent from hypertension.

\section{Limitations of the study}

In this study, the sample size of participants was small, and so the results may be biased; hence, a larger sample study needs to be undertaken.

\section{CONCLUSION}

The allele $G$ of MSA2756G is a risk factor for hypertension in the female Chinese population studied, but no association was found with men in the same population.

\section{DECLARATIONS}

\section{Acknowledgement}

The authors thank Xiong Jia, Huazhong of University of Science and Technology for expert technical assistance.

\section{Conflict of Interest}

No conflict of interest associated with this work.

\section{Contribution of Authors}

The authors declare that this work was done by the authors named in this article and all liabilities pertaining to claims relating to the content of this article will be borne by them.

\section{REFERENCES}

1. Kearney $P M$, Whelton $M$, Reynolds $K$, Muntner $P$, Whelton PK, He J. Global burden of hypertension: analysis of worldwide data. Lancet 2005; 365: 217-223.
2. Ueno $T$, Tabara $Y$, Fukuda $N$, Tahira $K$, Matsumoto $T$, Kosuge K, Haketa A, Matsumoto K, Sato Y, Nakayama $T$, et al. Association of SLC6A9 gene variants with human essential hypertension. J Atheroscler Thromb 2009; 16: 201-206.

3. Li M, Zhang B, Li C, Liu J, Liu Y, Sun D, Ma H, Wen S. The Association of Mitofusion-2 Gene Polymorphisms with Susceptibility of Essential Hypertension in Northern Han Chinese Population. Int J Med Sci 2016; 13: 39-47.

4. Kato N. Genetic analysis in human hypertension. Hypertens Res 2002; 25: 319-327.

5. Moskau S, Farmand S, Semmler A, Wüllner U, Pohl C, Klockgether T, Linnebank M. The methionine synthase polymorphism c.2756A>G (D919G) influences diastolic blood pressure. J Hum Hypertens 2007; 21: 418-420.

6. Jiang $S$, $Y u Y$, Venners $S A$, Zhang $Y$, Xing $H$, Wang $X$, $X u X$. Effects of MTHFR and MS gene polymorphisms on baseline blood pressure and Benazepril effectiveness in Chinese hypertensive patients. J Hum Hypertens 2011; 25: 172-177.

7. Zhang $Y$, Zhang M, Niu T, Xu X, Zhu G, Huo Y, Chen C, Wang $X$, Xing $H$, Peng $S$, et al. D919G polymorphism of methionine synthase gene is associated with blood pressure response to benazepril in Chinese hypertensive patients. J Hum Genet 2004; 49: 296-301.

8. Jain S, Ram H, Kumari S, Khullar M. Plasma homocysteine levels in Indian patients with essential hypertension and their siblings. Ren Fail 2003; 25: 195201.

9. World Medical Association. World Medical Association Declaration of Helsinki: Ethical Principles for Medical Research Involving Human Subjects. Seoul: From the 59th World Medical Association Assembly, 2008. http://www.wma.net/en/30publications/10policies/b3/17c .pdf.

10. Chen C, Gan YY. The allele frequencies of three polymorphisms in genes involved in homocysteine metabolism in a group of unrelated healthy Singaporeans. Dis Markers 2010; 29: 111-119.

11. Sirachainan $N$, Wongruangsri $S$, Kajanachumpol $S$, Pakakasama S, Visudtibhan A, Nuchprayoon I, Lusawat A, Phudhicharoenrat S, Shuangshoti S, Hongeng S. Folate pathway genetic polymorphisms and susceptibility of central nervous system tumors in Thai children. Cancer Detect Pre 2008; 32: 72-78.

12. Kim HN, Kim YK, Lee IK, Lee JJ, Yang DH, Park KS, Choi JS, Park MR, Jo DY, Kim HJ. Polymorphisms involved in the folate metabolizing pathway and risk of multiple myeloma, Am J Hematol 2007; 82: 798-801.

13. Morita $H$, Kurihara $H$, Sugiyama $T$, Hamada $C$, Kurihara Y, Shindo T, Oh-hashi Y, Yazaki Y. Polymorphism of the methionine synthase gene: Association with homocysteine metabolism and late-onset vascular diseases in the Japanese population, Arterioscler Thromb Vasc Biol 1999; 19: 298-302.

14. Conroy JM, Trivedi G, Sovd T, Caggana M. The allele frequency of mutations in four genes that confer enhanced susceptibility to venous thromboembolism in 
and unselected group of New York state newborns. Thromb Res 2000; 99: 317-324.

15. Shekari $M$, Sobti RC, Kordi Tamandani DM, Suri V. Impact of methylenetetrahydrofolate reductase (MTHFR) codon (677) and methionine synthase (MS) codon (2756) on risk of cervical carcinogenesis in North Indian population. Arch Gyneco Obstet 2008; 278: 517524.

16. Huang L, Song XM, Zhu WL, Li Y. Plasma Homocysteine and Gene Polymorphisms Associated with the Risk of Hyperlipidemia in Northern Chinese Subjects. Biomed Environ Sci 2008; 21: 514-520.
17. Kahleová R, Palyzová D, Zvára K, Zvárová J, Hrach K, Nováková I, Hyánek J, Bendlová B, Kozich V. Essential hypertension in adolescents: association with insulin resistance and with metabolism of homocysteine and vitamins. Am J Hypertens 2002; 15: 857-864.

18. Brett SE, Jiang BY, Turner C, Ritter JM, Chowienczyk PJ. Elevation of plasma homocysteine by methionine loading increases the diastolic blood pressure response to exercise. J Hypertension 2006; 24: 1985-1989.

19. Semmler A, Simon M, Moskau S, Linnebank M. The methionine synthase polymorphism c.2756A>G alters susceptibility to glioblastoma multiforme. Cancer Epidemiol Biomarkers Prev 2006; 15: 2314-2316. 